\title{
QUALITY OF LIFE IN EGYPT: WALKABILITY ASSESSMENT IN EL-MANSHEYA SQUARE, ALEXANDRIA, EGYPT
}

\author{
AYMAN MAHMOUD EL-ZEMRANY \& RANA ASHRAF ABDELKADER KANDIL \\ College of Architectural Engineering and Environmental Design Department, Alexandria University, Egypt
}

\begin{abstract}
Quality of life is an important aspect of liveability in cities. Being able to walk means there is less energy consumption, a stronger local economy and better health, thus better economic and social status. We aim to identify the role of walkability in city centers: How walkable is the city of Alexandria, Egypt? How do people feel about walking in the city? This research reviews how walkability develops in a city and has identified how the people in the central business district (CBD) of Alexandria travel through it. Walkable communities help cut greenhouse gas and other emissions by encouraging less driving, improving citizen's health by providing more walking opportunities, reduce crime by increasing social interaction, and support the local economy by encouraging shopping in the city center. The main problem is the decrease in walking rates in the CBD of Alexandria. Our research uses a questionnaire to identify the proportion of people living or working in the CBD, what means of travel they use, how long their journey is between home and the $\mathrm{CBD}$, and what walkability issues they face. This paper is of great importance to planners and decision-makers, showing how people behave in the historic CBD of Alexandria.

Keywords: Alexandria, city, central business district, Egypt, quality of life, sustainability, urban planning, walkability.
\end{abstract}

\section{INTRODUCTION}

The current world population is growing rapidly at an unprecedented rate [1]. The researchers found that more than half of the world's population is living in city central business districts (CBDs) like the CBD in Alexandria, Egypt. The new scale of rapid growth in city centers for those who live, work and do business in it add economic activities and employment opportunities, becoming a source of attraction to citizens, for making a new lifestyle [1]. A city center needs attraction nodes such as a residential area for citizens to live and places for entertainment, to increase the local economy. When the population density is growing, especially in the city center, thus expanding the boundaries of cities to absorb the increased population yet avoid congestion within the center of the city. The sprawling of cities demands an increase in movement between different parts, which has imposed constraints on time, energy and finances. This helped fuel dependency on private vehicular transportation, but it represents the main issues of pollution creation through the use of the automobile transportation system and changes in the travel pattern within the city center.

Rapid urbanization has imposed a big challenge to make liveable cities which expand, resulting in urban sprawl that encroaches into environmentally sensitive areas in the countryside [2].

In Egypt, Alexandria's city center El-Mansheya is one of the older parts of the city. There is a big change between the 19th and 20th century, when becoming the city's main center of administration and business district. The headquarters of Alexandria's government and the Alexandria court of appeal are both in the El-Mansheya region. Also, the Alexandria offices of the Egyptian exchange are located in El-Mansheya; so most economic activities take place in the CBD. This situation causes a complex travel pattern and commuting trend, because of 
the trip origins and destination that are all over the place [3], where currently there is a heavy dependence on private vehicles as the transportation mode (Fig. 1).

Urban planners have proven that the high energy consumption in Alexandria comes from the transportation (which is $31 \%$ ) and commercial/industrial sectors (46\%), while the other sectors use between $1 \%$ and $20 \%$; this shows that the city of Alexandria city is far away from having a sustainable environment, as the transportation and commercial/industrial sectors are the biggest contributors towards the quality of life provided to the surrounding environment [4] (Fig. 2).

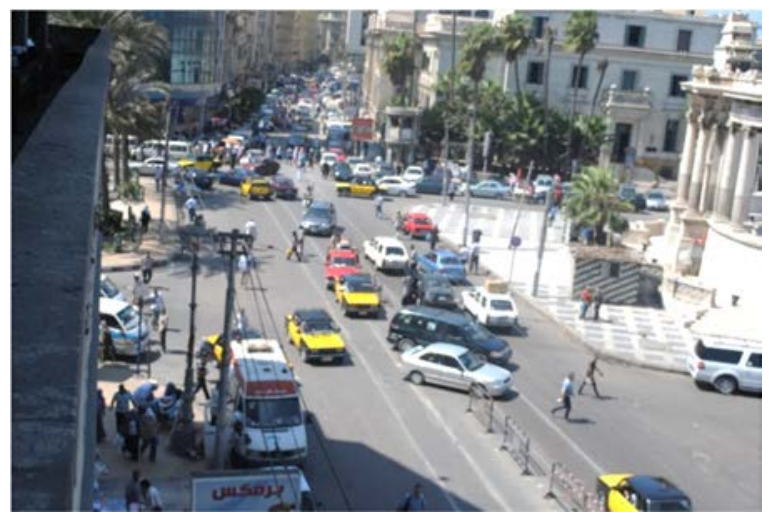

Figure 1: This image shows people in the central business district (CBD) of Alexandria, Egypt, using their own private vehicles, as well as public transportation. (Source: Researcher, 2019.)

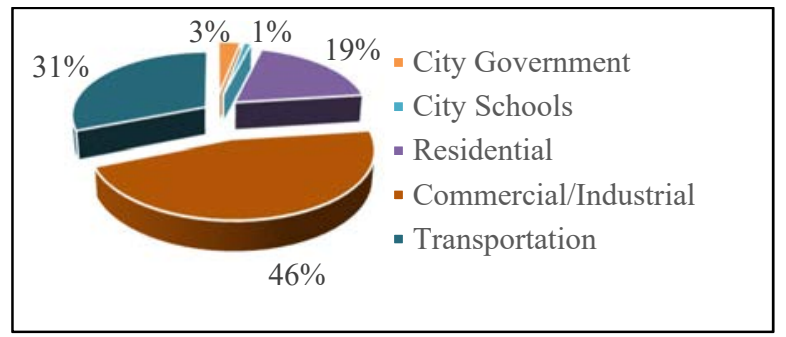

Figure 2: Greenhouse gas (GHG) emissions and energy consumption by sector, as a percentage of the total for Alexandria, Egypt [4].

Our research hypothesis is that stress could be generated by the built environment, that means less walking is becoming the result of the built environment, providing problems such as: congestion, sleep problems, no street furniture, no activities, a lot of skyscrapers surrounding the area; all these problems are causing depression to pedestrians in the street. So, stress is an important factor to citizens, as this may have contributed towards making people walk less.

According to other studies, the citizens have used private vehicles more than public transportation, and they walk as a short means of transport within the CBD of Alexandria, so this proves that people are tending to choose cars rather than walk, even though Alexandria 
is known as an area of tourist attraction. Apart from improving public transportation in the CBD of Alexandria, a walkable city is also important in creating a livable city. Therefore, the creation of a walkable environment helps, where people or tourists can know the features about the place they live in or if visiting the CBD. In addition, walkability will improve the quality of life of the citizens by promoting a healthy lifestyle. The aim of this research is to identify the role of walkability in the city CBD.

Our objectives are as follows: to investigate what the role of walkability is through studying the theories, concepts, and definitions, deduce a conceptual model from understanding the role of walkability that correlates with the livability, sustainability, and walkability situation within city, investigate and study the main parameters of this model from the urban field literature, Use a questionnaire to assess the level of comfort by citizens in Alexandria city within $\mathrm{CBD}$, and finally, to propose a guidelines to respond to the evaluation and public opinions.

\section{LITERATURE REVIEW}

The researchers define that liveability is one of the aspects that contribute to increasing the quality of life. Most city centers in the world were faced with the challenge in keeping the city safe, increasing health conditions and economic stability, as well as providing a good transportation system and road network [5]. There are a lot of definitions for liveability: one of them is that a "city through good planning, provides a vibrant, attractive and secure environment, high quality of living and environmental sustainability" (Fig. 3) [6].

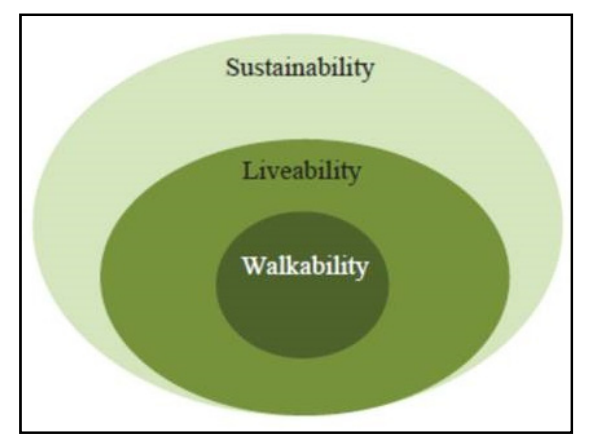

Figure 3: The sustainability, liveability and walkability connection [5].

Liveability is a part of the sustainability concept that consists of different objectives, one of these objectives is to promote a walkability environment, that is, to have more accessible areas and more transportation choices in the cities [7]. This shows that walkability is a part of the liveability concept, which helps promote sustainability living. A city with liveability promotes sustainable transportation, which is to reduce noise and air pollution, as well as encourage citizens to walk [8]. The word "ability" is defined as the "fact that somebody or something is able to do something" [9].

Walking is the most basic and common mode of transportation and is recommended for a healthy lifestyle, as the health epidemic of the 21 st century, and also walking has numerous environmental benefits. When distances are too great to be convenient, walking can be combined with other modes of transportation, such as: cycling, public transport, car sharing, or driving a car [10]. 
There has been a recent focus among urban planners in some communities to create pedestrian-friendly areas and roads, allowing for commuting, shopping and recreation to be done on foot. For example, the US promoted having an active living network by improving walkability in communities. Walking is considered as an example of a sustainable mode of transport; and non-motorized transport modes such as walking, but also cycling, smallwheeled transportation devices or wheelchair travel are successful elements for achieving a sustainable mode of transport and clear urban transport [11]. A large variety of case studies and good practices (from European cities and some worldwide examples) that promote walking as a means of transportation in cities can be found at ELTIS, Europe's portal for local transport [12].

Stephen [13] stated that, "the built environment with walkability and public health, it is important to understand what elements of the built environment contribute to walking ability". Many elements encourage walking activities; such as enjoyable elements, pedestrian facilities, and more. Besides, cities and streets consist of different pavements and networks; because of this, it has helped in classifying different categories that can achieve walkabilitybased communities, such as: land use, accessibility, traffic safety, walking and cycling comfort, and more [14]-[16]. This shows how to create a walkable environment, to create a space that is convenient and makes the citizens enjoy walking, making the city center more livable. The purpose of creating a livable city with a walkable environment became one of the elements in creating the livability of a place [17].

\section{RESEARCH METHODOLOGY}

This research identifies the role of a walkable environment in making El-Mansheya, Alexandria a livable city. Walkability in this research is defined as increasing the quality of the walking environment that provides comfortable needs to pedestrian users of El-Mansheya Square.

In order to conduct the analysis of the walkability assessment in the El-Mansheya region, this research is divided into two approaches, a deductive approach and a qualitative approach. In the first method, researchers reviewed the urban literature (deductive approach) such as journal articles, web pages, books and research papers; to identify their research framework. For the second method, the researchers employed a questionnaire to survey 350 users of Alexandria's city center, to assess the level of comfort according to users of that city center. The users and the respondents may or may not live in the city center, but are using the city center as a place of work, to live, for shopping, entertainment, etc. The assessment provided valuable insights on decision-making processes, and on how sustainable urban policies can be proposed. The questionnaire survey covered many areas, not only the city center (Table 1).

Table 1: City center survey of locations and districts. (Source: Researcher, 2019.)

\begin{tabular}{|c|l|l|}
\hline Zone & Location & District \\
\hline 1 & El Mansheya Square & Residential - Commercial - Office \\
\hline 2 & Zana'at el satat & Shopping area \\
\hline 3 & Lauran & Residential - Commercial \\
\hline 4 & Abu Qir & Education \\
\hline 5 & El Mansheya, Gesh Street & Court - Commercial - Residential \\
\hline
\end{tabular}




\section{RESULTS AND DISCUSSION}

A sample survey of 350 respondents from five different zones was conducted, to evaluate the level of comfort in walking in the city center of Alexandria. The majority of the respondents $(62 \%)$ work inside the CBD of Alexandria, and that means there is movement in and out of El-Mansheya (Fig. 4). According to the analysis, it is proved that some people come to the CBD of Alexandria for other services, such as shopping, going to Alexandria court, entertainment, banking, coming for tourism, students doing research about historical buildings, etc. So, the role of the El-Mansheya district is also considered as an activity center, especially in terms of economics and entertainment.

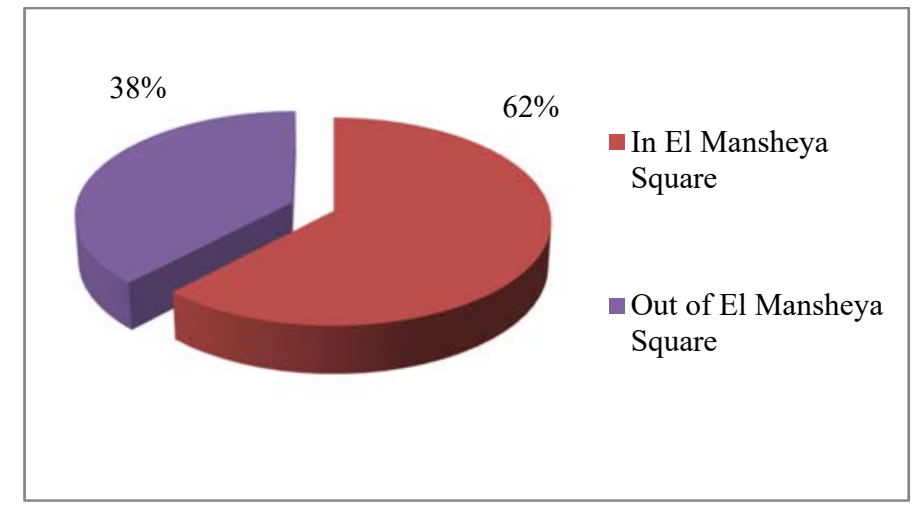

Figure 4: Respondent working areas in relation to El Mansheya Square in Alexandria, Egypt. (Source: Researcher, 2019.)

It was observed that the majority of the citizens who lived outside El-Mansheya and worked in different areas inside the city are busy travelling. During the peak hours between 7 am and 9 am in the morning, and between $2 \mathrm{pm}$ and $4 \mathrm{pm}$ in the evening, it was observed that there was congestion in all zones, with all types of vehicles. It was also observed that the majority of users are using their own private vehicles, as the citizens' housing areas are located around 40-45 minutes of driving time/distance from their place of work.

Fig. 5 shows that the majority of the survey respondents (43\%) use their own private cars to go from home to their offices. This causes an increase in the opportunities to make a more livable environment, as a high dependency on private vehicles will lead to high energy consumption, other emissions such as carbon dioxide, and contribute to an unhealthy environment and quality of living; however, there is still a huge number of survey respondents who do choose to travel by public transportation (39\%), because they have no other choice. Although there are a few respondents who choose to travel a short distance within the city center by walking, about $18 \%$, and this means that El-Mansheya can be and is a walkable region in the future and in the present.

The survey respondents who are choosing a public transport mode for travelling and how many trips it takes to go to their destinations places the majority of the citizens with the need for one or two public transports to reach their workplace in the CBD of Alexandria number about $86 \%$, but there are a few who need three to five transport modes $(9 \%)$ or more. Our research found that users were not living far from the city center, and this means that in the future when there will be reduced capacity to go in private vehicles, they can try using public transportation, then walking, which leads to sustainable living (Fig. 6). 


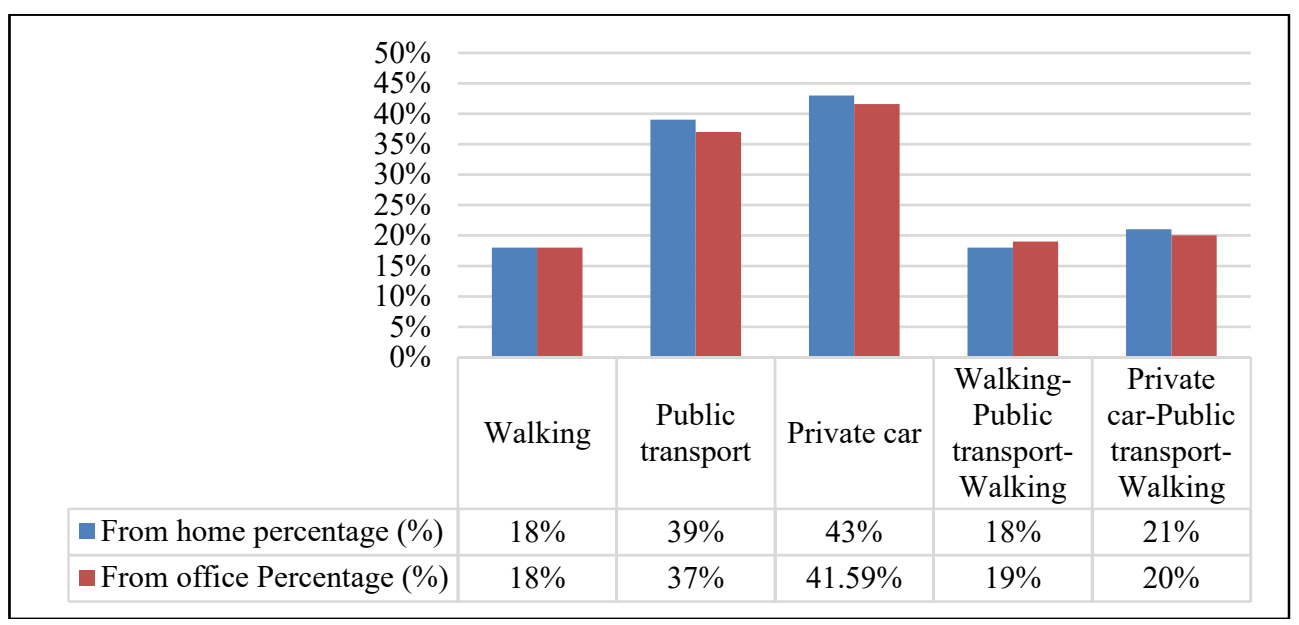

Figure 5: Travel patterns for the public going through El Mansheya square, Alexandria. (Source: Researcher, 2019.)

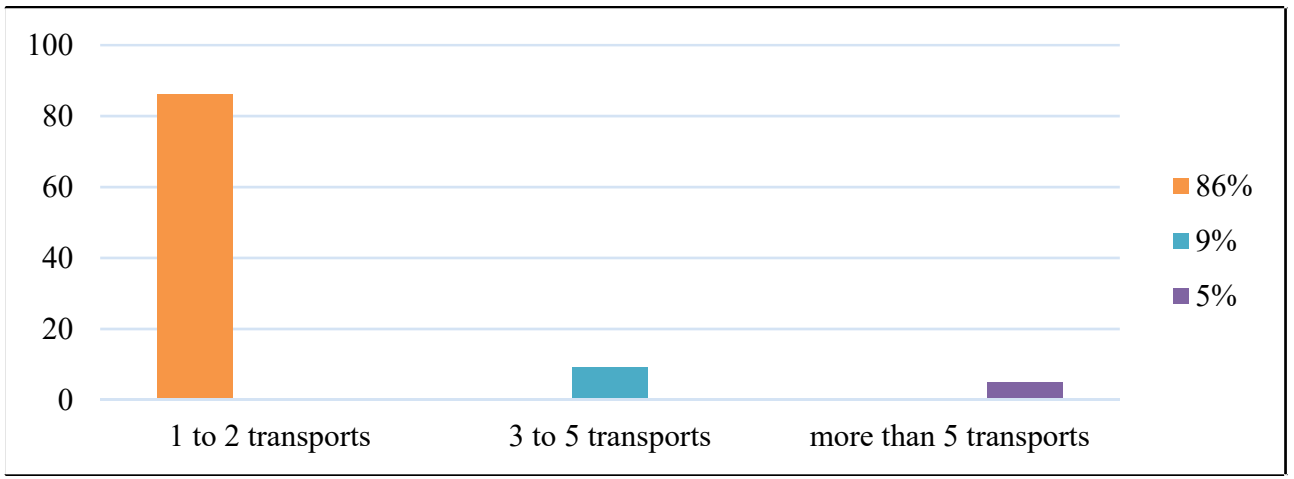

Figure 6: How many trips does it take to go to a respondent's home or job/s? (Source: Researcher, 2019.)

Alexandria's role as a business district and also one of the tourist attractions is also a contributing factor in having a high degree of movement within the CBD of Alexandria; however, $49 \%$ of the respondents admitted that they do not like to squeeze in along with other users of public transportation, such as the tram and public buses, which leads them to drive their own private cars, as they can always stay comfortable and find safety in them.

The findings, however, are related to the lifestyle of the citizen itself, as well as their level of income. Actually, a high percentage (49\%) do select to drive to work, as these people do not like being in a crowded place, suggesting that there may be a high degree of demand for public transportation. The area is supposed to increase in public transportation provision, as that contributes toward reducing the high number of private cars users (Fig. 7).

In fact, the citizens prefer driving their own private cars instead of any mode of transportation, due to the fact the streets are not paved and this is not seen as suitable for 


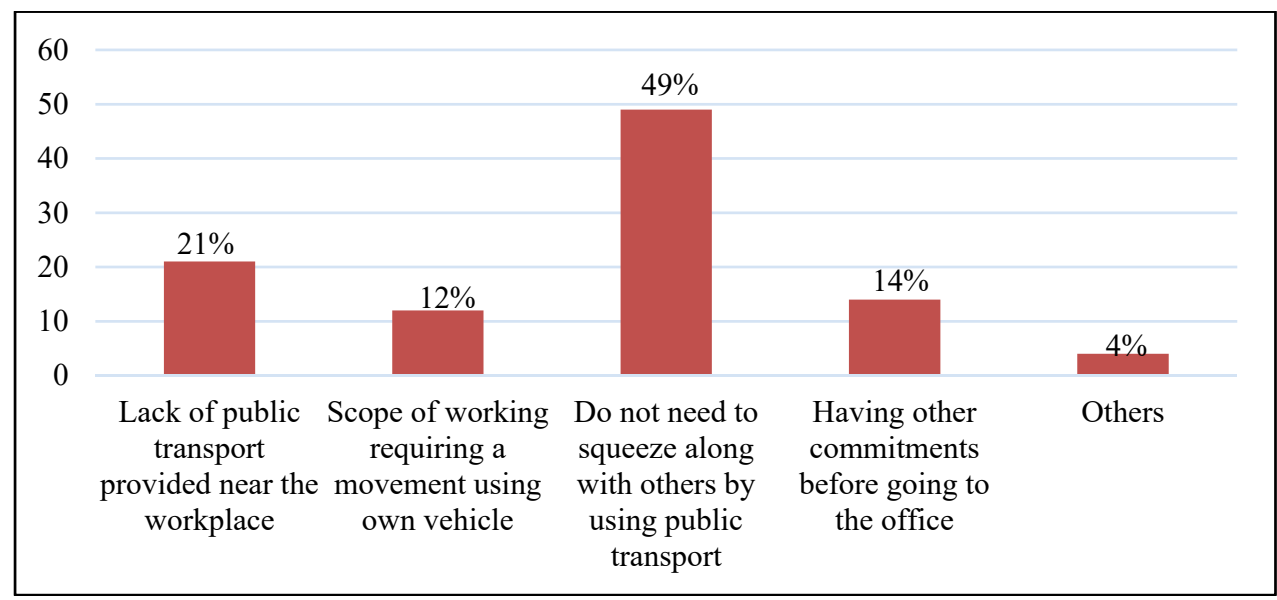

Figure 7: People's reasons for using their own private vehicles. (Source: Researcher, 2019.)

walking, no street furniture existed either nor even activities, there is a lack of safety, bad attitudes by taxis drivers as well as the public transportation drivers, there is provocation present, etc. Of the respondents, $56 \%$ thought that there is a problem to use walking as the form of short transportation within the city center and it proved that the users do not like to be in crowded places and have difficulty in crossing the roads, as there are no suitable pathways nor roads for people to walk in; and on the other hand, there is a huge quantity of people who would like to use a walk as a transportation mode (44\%), when El-Mansheya is made suitable for pedestrian users, and this will help achieve a livable city status in ElMansheya, by improving it to be a walkable environment.

A majority of more than $45 \%$ had a problem in walking for many reasons; but at the same time, the people from 18 to 25 would like to be able to walk and they do not have any problem with walking, but under improved conditions, such as by constructing pedestrians' pathways, intersection signals for traffic, and more (see Fig. 8).

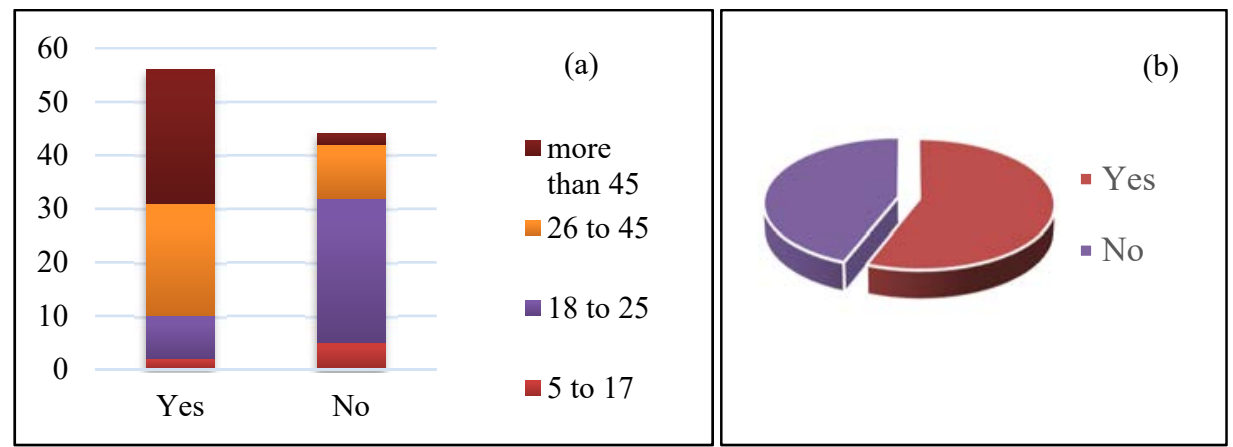

Figure 8: Questionnaire feedback. (a) When asked if the respondents think about whether there is a problem for them to use walking as a short mode of transportation, by respondent age group; (b) Asked if the respondents think about whether there is a problem for them to use walking as a short mode of transportation. (Source: Researcher, 2019.) 
The users may have their own opinions about the notion of walking the CBD of Alexandria. Based on observations, only at chosen places within Alexandria are there comfortable walking paths that can be found that allow them to walk continuously. Although in Fig. 9, 28\% of respondents do not like to walk in the CBD to not be in a crowded place due to feeling unsafe, $23 \%$ of respondents said that they have difficulty in crossing the roads. Fig. 9 shows that $19 \%$ of respondents agree that they prefer to use their own private vehicle, and $11 \%$ of the respondents said that walking is tiring for them; so therefore, they choose not to walk inside the city, no matter how convenient the place is. We found that $11 \%$ of respondents do not like to walk when the weather is hot and they become sweaty.

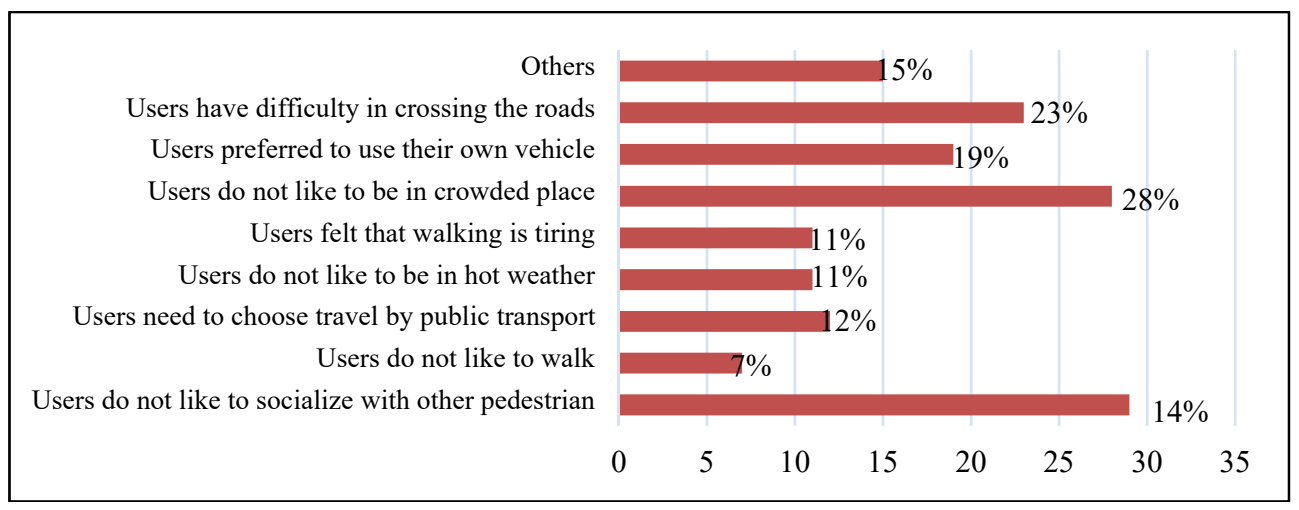

Figure 9: Why Alexandria citizens think it is a problem to walk in the CBD. (Source: Researcher, 2019.)

From the survey, the researchers also found that only $14 \%$ do not like to socialize with other pedestrians. This is related to the behavior pattern of the citizens, where the CBD is probably seen as a place for them to work, rather than as a place for them to interact. This perspective is not healthy, if citizens are to encourage the making of a public realm to inject some life and activities into the city center. It could also be that the CBD fails to provide an environment that encourages social interaction to happen in the city center of Alexandria. On the other hand, we found that $12 \%$ of the respondents need to choose to travel by public transportation and that only a few of the respondents (7\%) do not like to walk through the $\mathrm{CBD}$ of the city.

There were also other reasons, as $15 \%$ of the respondents said that the distance is far between their home and work, between school and home, and in addition that the streets are causing stress on the citizens in the CBD for walking, due to the street vendors, obstacles in the pavements, people bad attitudes, and more.

In order to promote this walkable lifestyle, there are a variety of elements needed to support a walkable environment in the CBD, according to the users' needs. Fig. 10 shows that the majority of the respondents $(32 \%)$ agree that pedestrian walkways are the most essential element that is required to encourage walking activities in the El-Mansheya region. Only certain areas in Alexandria city are comfortable and have wide walkways provided, and others have relied on the remaining width of the streets to be turned into walkways.

Destinations in the area also lead to making it essential to have the environment walkable, a place with a high amount of users need better quality walkways for the citizens to use places 


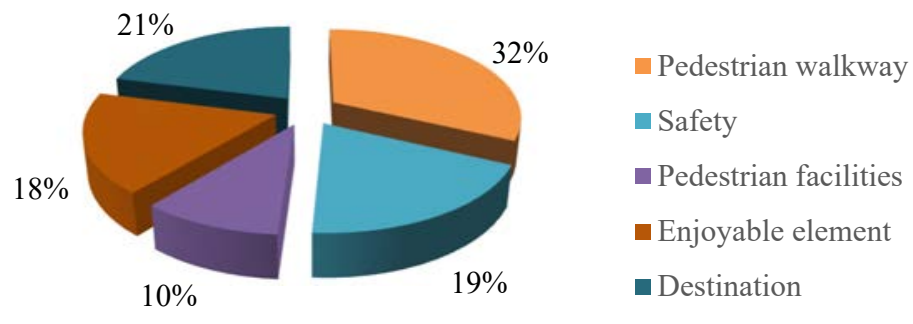

Figure 10: Elements that encourage walking activities. (Source: Researcher, 2019.)

frequently. Based on our observation, lots of movements that need people to be walking do happen in the Alexandria shopping district, as it is along Zanaat el satat, Syria market, French street, etc. Within this area, it only takes 15-20 minutes to walk from one place to another. In addition, there were $19 \%$ of respondents who said that they need to feel safe while walking in the city center, so the survey respondents show that improving the enjoyable element and pedestrian facilities would help in encouraging walking in the El-Mansheya area (about 28\% of respondents said this).

We found that $34 \%$ of respondents agree that El-Mansheya is not safe for walking nowadays, while $25 \%$ of respondents said that El-Mansheya is safe, so the research found that citizens should be provided with pedestrian pathways with a suitable street width, to force people to interact, as at a certain point "social interaction" helps in reducing crime; and also, there should be pedestrian facilities such as illumination, protection where the street is narrow, etc. for the pedestrian to walk comfortably, feel comfortable. A huge number of respondents agreed that if these elements were achieved in El-Mansheya, they could walk comfortably (Fig. 11).

Walking is healthy for pedestrians users such as for practicing exercise, making activities, etc., but there are some of respondents who do not like to walk as a sport nor as a transportation mode; and this category referred mostly to those who are older than 50 years; while the majority of the respondents (56\%) agreed walking is good and $25 \%$ strongly agreed about using walking as both a daily sport and as a transport mode. The research found from

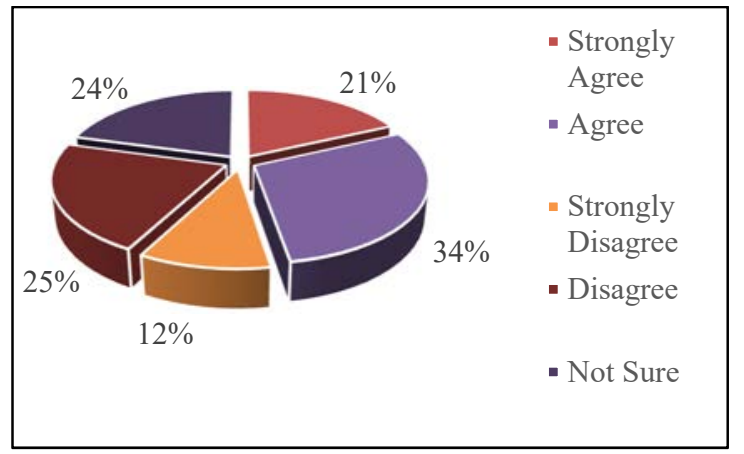

Figure 11: Is El-Mansheya considered walk-friendly? (Source: Researcher, 2019.) 
these results that to maintain a special pathway for the handicapped, as put in consideration, and for the people who are older to be able to move slowly as they age (Fig. 12).

There are other additional elements which pedestrians need for achieving walkability in the communities within the CBD of Alexandria (Fig. 13). From our survey, we found that $18 \%$ of respondents need the place to be comfortable and have appeal, and not feel stress while walking. That is also why the citizens need to improve the driver behaviors of public transportation modes or even in those who own private vehicles, as this impacts on the quality of life of citizens. In addition, there is the need to create pedestrian traffic signals at intersections.

If we should achieve all the elements that respondents need to achieve walkability in communities, we will help them in walking comfortably. These elements will be done when the attitude of the people in the street changes for the better, with increasing the awareness of the citizens towards the necessity of having a walkable environment and community.

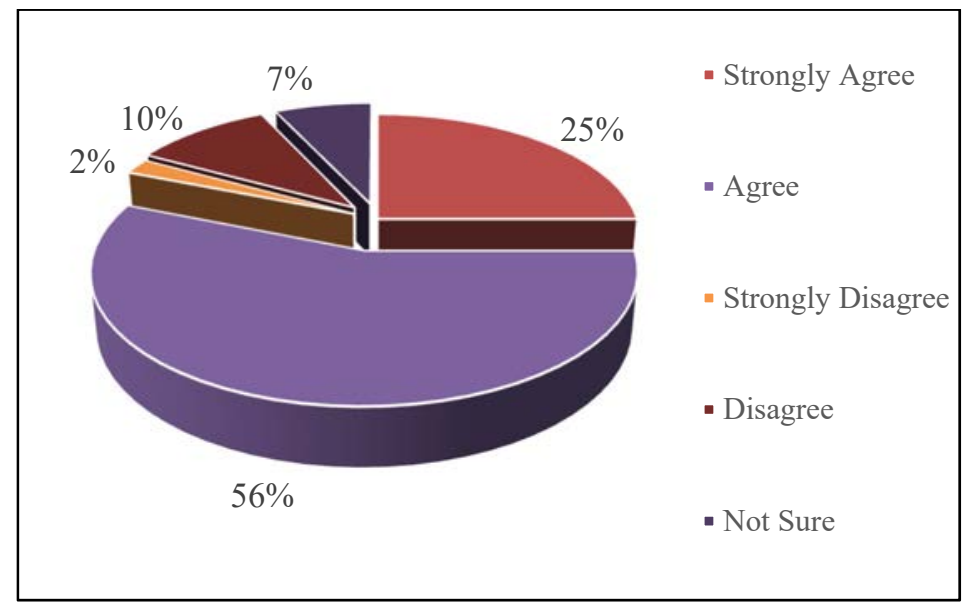

Figure 12: The percentage of respondents who agree with using walking as a sport, daily, and as a transport mode. (Source: Researcher, 2019.)

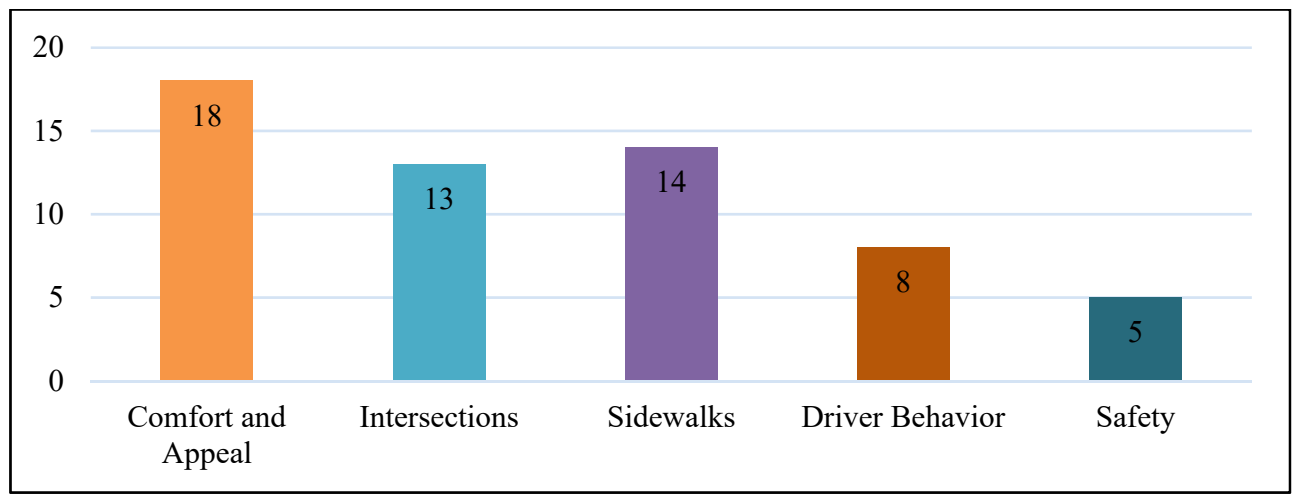

Figure 13: Elements respondents say they need to achieve walkability in the CBD communities in Alexandria, Egypt. (Source: Researcher, 2019.) 


\section{CONCLUSIONS}

The inclusion of Egyptian cities within the world of livable cities expands the chances for tourism and other forms of foreign investment. To be recorded within the list of the worlds' most livable cities is one of the key variables that may appear to show how Egypt is getting to be a choice for foreigners as a place to live in. This has brought alterations within the policy-making that conjointly impacts Egypt's approach towards advancement. Hence, the policies and regulations with respect to the nation are being remade to bring benefits in terms of economic activities, as the impact of Alexandria city to the world creates it as more amiable for speculators to contribute to this nation.

Quality of life in the city center could be achieved for people through placing the priority of safety and comfort, which means people need a walkable city and livability in their community. There are some principles for achieving a walkable environment that reduces the use of private cars and allows for easy access with no obstacles along the walking paths. ElMansheya is always congested during peak hours.

Our research is focused on El-Mansheya Square as a case study, due to its attractions involving major pedestrian users; namely shoppers, visitors, street vendors, students, workers, bankers, lawyers, accountants and more. The limitation of this study is to be able to evaluate the variables that create the resident's selection to walk within the CBD, rather than evaluating the walkability from the criteria for a walkable environment. Hence, this limitation means that it is the discernment of the pedestrians that is being examined, instead of the traits from the environmental perspectives in making a walkable environment.

This research depends on the walkability assessment in Alexandria's city center, as it is considered the second largest city in Egypt. The paper is focused on El-Mansheya, as it is a city center featured by its economic activities. Consequently, the thought of making a walkable environment is critical, so that we can assist to form a comfortable place to live within. The research displays that transportation has gotten to be an issue that must be tended to. This needs full bolstering from the local and non-government organizations, to make sure it can succeed. This study shows that the lack of walkable components has influenced the behavior of walking among the citizens.

There is no simple arrangement, as numerous zones were set up way before policies had been created. It is gotten to be, curiously, due to the interest from architects, planners and the government itself to plan new areas and upgrade existing zones. In any case, the genuine issue is the lack of awareness among the citizens themselves, and this is exacerbated by the lack of support from the government to encourage the citizens to walk in the CBD. A strict assessment was required to constrain alterations in attitude, and maybe it all can be changed by the design of the CBD's environment itself. It is proposed that further research is required to evaluate the efficiency of the policies we have in promoting citizens to walk in the CBD, as this may impact why there is still an unwillingness to walk among the citizens. The research conclusions were that stress occurs as a result of misfitting between the person and the environment, in which case it is the misfit found between the users' needs and the actual street environment.

\section{REFERENCES}

[1] Urban Planning Advisory Team (UPAT), International Society of City and Regional Planners (ISOCARP), for the Philips Centre of Health and Well-being. www.meaningfylinnovation.philips.com. Accessed on: 15 Jun. 2019.

[2] Evan, P., Liveable Cities: Urban Struggles for Livelihood and Sustainability, University of California Press: London, 2002. 
[3] Central Agency for Public Mobilization and Statistics, Alexandria yearly statistical report. www.capmas.gov.eg. Accessed on: 30 May 2019.

[4] Department of Transportation and Environmental Services, City of Alexandria Energy and Climate Change Action Plan 2012-2020, Office of Environmental Quality: Alexandria, 2015.

[5] Economic Intelligence Unit, A summary of the liveability ranking and overview, 2011. www.eiu.com. Accessed on: 30 May 2019.

[6] Shuhana, S., Nur, R. \& Siti, F., Walkable environment in increasing the liveability of a city. Conference on Environmental and Behaviour Studies, 50, pp. 167-178, 2012.

[7] Victoria Transport Policy Institute (VTPI), Transport strategies and plan. Department of Transport, State Government of Victoria, Australia, 2015.

[8] Lennard, S.C. \& Lennard, H., The principles of true urbanism. www.livablecities.org. Accessed on: 1 Jul. 2019.

[9] Oxford Advance Learner Dictionary, Oxford University Press: UK, 2010.

[10] Department for Transport of UK, Statistics. www.dft.gov.uk. Accessed on: 15 Jul. 2019.

[11] Non-Motorised Transport, Teaching, and learning material. www.eu-portal.net. Accessed on: 22 Jul. 2019.

[12] Litman, T., Measuring transportation: Traffic, mobility and accessibility. ITE Journal, 73(10), pp. 28-32, 2016.

[13] Stephen, M., A Better Urban Design of Cities is Closely to Sustainable Planning, Routledge, 2012.

[14] Carmona, M., Heath, M.T., Oc, T. \& Tiesdell, S., Public Spaces Urban Spaces, The Architectural Press: New York, 2003.

[15] Dantzig, G.B. \& Saaty, T.L., Compact City, A Plan to Liveable Urban Environment, W.H. Freeman: San Francisco, 1973.

[16] Steve, A., Walkability scoping paper. www.levelofservice.com/walkabilityresearch.pdf. Accessed on: 19 July 2019.

[17] Global Transformation Program (GTP), Global Transformation Program Annual Report 2010, Performance Management and Delivery Unit (PEMANDU). www.pemandu.gov.my/gtp/upload/GTP_AR2010_Eng.pdf. Accessed on: 20 Jun. 2019. 